\title{
Implementation Science and Implementation Science Communications: our aims, scope, and reporting expectations
}

\author{
Anne E. Sales ${ }^{1,2^{*}}$ D, Paul M. Wilson ${ }^{3}$, Michel Wensing ${ }^{4}$, Gregory A. Aarons ${ }^{5}$, Rebecca Armstrong ${ }^{6}$, Signe Flottorp ${ }^{7}$, \\ Alison M. Hutchinson ${ }^{8}$, Justin Presseau ${ }^{9}$, Anne Rogers $^{10}$, Nick Sevdalis ${ }^{11}$, Janet Squires ${ }^{12}$, Sharon Straus ${ }^{13}$ \\ and Bryan J. Weiner ${ }^{14}$
}

\begin{abstract}
In the 13 years since the inception of Implementation Science, we have witnessed a continued rise in the number of submissions, reflecting the growing global interest in methods to enhance the uptake of research findings into healthcare practice and policy. We now receive over 800 submissions annually, and there is a large gap between what is submitted and what gets published. To better serve the needs of the research community, we announce our plans to introduce a new journal, Implementation Science Communications, which we believe will support publication of types of research reports currently not often published in Implementation Science. In this editorial, we state both journals' scope and current boundaries and set out our expectations for the scientific reporting, quality, and transparency of the manuscripts we receive.
\end{abstract}

\section{Background}

In the 13 years since the inception of Implementation Science, we have witnessed a continued rise in the number of manuscripts submitted. We now receive over 800 submissions annually (see Fig. 1), reflecting the growing interest from researchers, funders, and health professionals and policy makers in promoting the uptake of research findings into healthcare practice and policy. The number of manuscripts published in Implementation Science has remained rather stable, between 120 and 150 per year.

The large gap between what is submitted and what gets published is driven by two key issues, namely scope and scientific quality. This editorial aims to address both of these issues and act as a further guide to researchers seeking to publish their work in Implementation Science and our new companion journal Implementation Science Communications.

\footnotetext{
* Correspondence: salesann@umich.edu

'Department of Veterans Affairs Center for Clinical Management Research, VA Ann Arbor Healthcare System, 300 N. Ingalls Street, Suite 1161, Ann Arbor, MI 48109-5430, USA

2Department of Learning Health Sciences, University of Michigan, Ann Arbor, USA

Full list of author information is available at the end of the article
}

\section{Scope and boundaries of Implementation Science}

In 2017, we reviewed and provided a detailed explanation and elaboration of our journal scope [1]. At that point, we did not expand the boundaries of our scope, and we continue to maintain the same scope. Our focus remains on the publication of studies examining the implementation of evidence-based healthcare interventions, practices, or policies, or the de-implementation of those demonstrated to be of low or no clinical benefit or even harmful. We retain a strong emphasis on reports of studies with strong study design and a high degree of rigor, across both quantitative and qualitative methods, including mixed methods.

For implementation effectiveness, we seek to publish studies that employ rigorous experimental or quasiexperimental designs regardless of whether they report effects or no effects. By rigorous, we mean those designs that would be eligible for inclusion in Cochrane EPOC reviews [2]. This can include type 2 or type 3 hybrid designs where there is a dual a priori focus on assessing clinical effectiveness and implementation strategies [3], but only where there is a clear justification and major component of implementation research. Type 2 hybrid designs have a dual focus on effectiveness and 


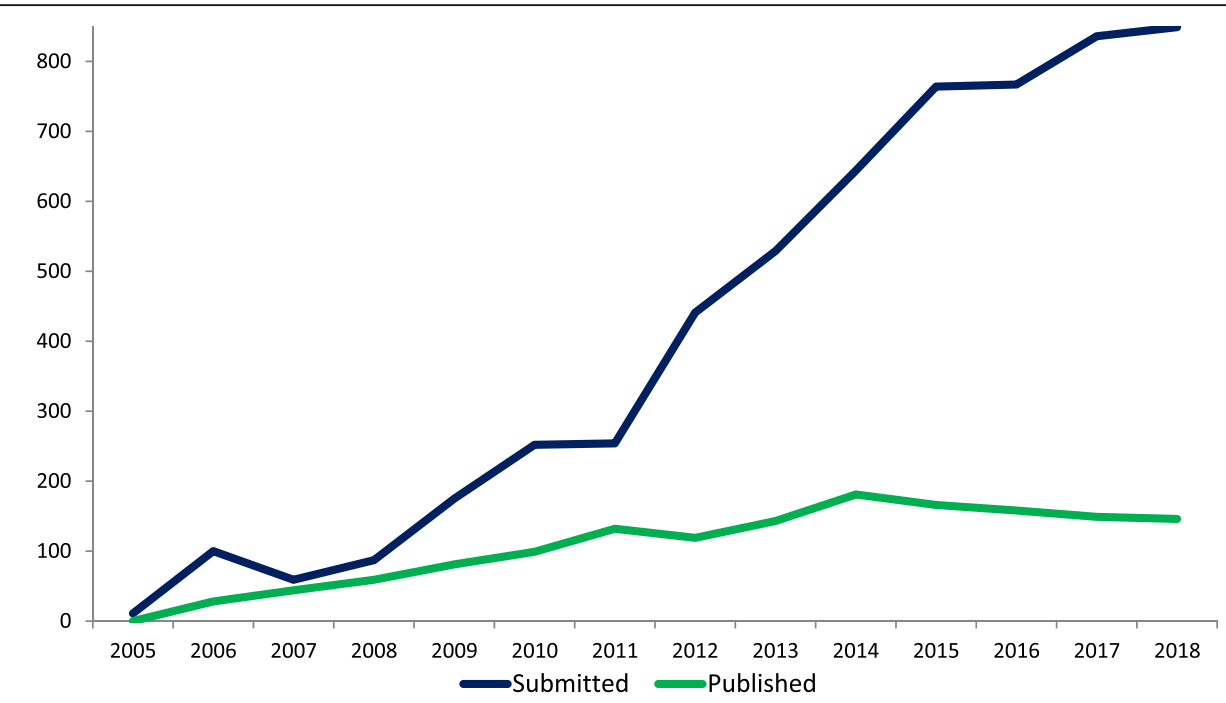

Fig. 1 Manuscripts submitted to and accepted for publication in Implementation Science 2005-2018

implementation outcomes, for example, testing both the effectiveness of brief cognitive behavioral therapy and the implementation strategies [4]. Type 3 hybrid designs have a primary emphasis on evaluating implementation, for example of a diabetes prevention program [5]; in such studies, data on clinical outcomes are also collected, as secondary or tertiary endpoints.

In addition to the above, we continue to receive a considerable number of manuscripts reporting studies testing novel clinical, service, or population health interventions; in such studies, the effectiveness of the intervention or practice has yet to be established. As our scope focuses on the implementation of interventions of demonstrated effectiveness, we routinely reject these manuscripts, offering transfer to other BMC journals. These exclusion criteria also apply to type 1 hybrid designs where the focus is on testing the effects of a clinical intervention on relevant outcomes while observing and gathering descriptive information on implementation [3]. Studies of this type fall outside of our journals' scope.

Implementation interventions are invariably complex, and so, alongside a rigorous evaluation of implementation effectiveness, we also welcome economic evaluations [6], process evaluations, and other qualitative research that examine different aspects of how an intervention functions in a given context and which contribute to our overall understanding of effectiveness. This includes the study of adaptation and fidelity, mechanisms of impact, and contextual influences on implementation and outcomes, sustainability, and scalability as well as the study of influences on the provider, patient, and organizational behavior. Crucially, we expect the methods employed in such studies to be an appropriate fit to the question(s) being addressed and to be informed by relevant conceptual frameworks [7-9].
We also welcome articles that present new methods and articles that question or challenge existing implementation policies, practices, evidence, or theory and suggest modifications or alternatives. However, it is worth noting that there is no shortage of frameworks and theories already developed and applied in implementation research [7-9]. So, rather than developing yet more frameworks or theories, our preference is for empirical studies that test and advance our understanding of how best to deploy the existing theoretical base [10]. With debate papers, we reject those that fail to ground the central argument within the existing implementation research literature. Most debate papers are of greater relevance if the arguments posed are based upon systematic reviews of the relevant evidence.

\section{Aims and scope: Implementation Science Communications}

We recognize that our current focus in Implementation Science on innovative, rigorous, and high-quality papers that contribute significantly and substantially to the accumulated knowledge in the science of implementation, coupled with our current scope, results in frequent rejection and offers to transfer to journals outside the discipline of implementation science. We are aware that many authors would prefer to publish in a journal that specializes in health-related implementation research. We are therefore launching Implementation Science Communications in 2019, to accommodate a wider range of types of study reports, and a somewhat broader scope. In doing so, we are emulating the broad goal of the BMC Series in their subject-specific journals, to make decisions primarily on the grounds of scientific validity (sound science), rather than broad interest or likely 
impact. Implementation Science Communications will accept manuscripts for which the audience may be narrower and more focused than the wider community of implementation or dissemination researchers. This includes the opportunity to consider manuscripts in areas that border on the general scope for Implementation Science or that are more descriptive than hypothesis-driven.

The new journal will be closely aligned with Implementation Science. There will be joint coordination and governance of both titles, and the co-Editors-in-Chief of Implementation Science Communications will be closely aligned with those of Implementation Science. All bring a commitment to the continued growth and development of the field of implementation research.

To clarify the scope and focus of the two related journals, Table 1 presents the types of manuscripts likely to be accepted by or rejected from Implementation Science and discusses how some manuscripts might fit well within Implementation Science Communications. This should assist prospective authors to judge which journal is the most suitable home for their implementation research.

\section{Sound science}

Alongside failure to meet scope requirements, poor scientific quality remains a common reason for rejection. Promoting the development, refinement, and quality of implementation research was a key aim of the founding Editors [11] and remains so today [1]. Across both Implementation Science and Implementation Science Communications, we will support and promote efforts to improve research quality and transparency as components of sound science.

\section{Prospective trial registration}

We support initiatives to improve the reporting of randomized trials. We have adopted the ICMJE recommendation [12] and normally consider for publication trials that have been registered with an appropriate publicly available trial database prior to enrolment of the first participant/cluster. Our expectation is that all trials will be prospectively registered.

While there are no fixed rules about the registration of other study designs, we strongly encourage authors of other outcome evaluations to register studies whenever possible. Researchers undertaking systematic reviews are advised to prospectively register their review with PROSPERO or another publicly accessible registry.

\section{Enhancing research reporting}

Over the last decade, we have routinely required authors submitting manuscripts reporting trials to Implementation Science to complete the CONSORT checklist or relevant extension. Similarly, a requirement to complete the PRISMA checklist has been enforced for authors submitting systematic reviews. No other checklists have been routinely or uniformly enforced. As a journal that receives manuscripts covering a wide range of study designs, variation in the standards of reporting of the research that we publish has been the result.

Because our aim is to promote research quality and transparency, as an aid to our readers, reviewers, and Editors, we now require authors submitting manuscripts to both journals (regardless of study design) to complete and include a design appropriate reporting checklist. This is true of both Implementation Science and Implementation Science Communications.

The website of the EQUATOR Network provides details of available reporting guidelines (www.equator-network.org). Authors of manuscripts (regardless of study design) should refer to EQUATOR and ensure that they complete and include a design appropriate reporting checklist with their submission. Table 1 includes details of our preferred reporting formats; for those research types where consensus is lacking on reporting format (for example, in qualitative research), we encourage authors to select their preferred checklist.

Improving the quality of intervention description is as much an issue for implementation research as it is for other evaluations of complex interventions. Without sufficient detail, it is difficult for readers to determine what was actually implemented and/or for other researchers to use or replicate the intervention in other studies. While TIDieR is most often used in conjunction with the CONSORT guidelines for trials [13], improved intervention description is relevant across all evaluative study designs [14]. Other relevant standards for reporting implementation interventions (Standards for Reporting Implementation studies - StaRI) and for reporting behavior change interventions (Workgroup for Intervention Development and Evaluation Research - WIDER) have been developed and are available. We strongly encourage authors to use the website of the EQUATOR Network to select their preferred guideline to enhance reporting of interventions.

\section{Contribution to the field}

With all submissions, we expect authors to clearly articulate what is already known and what their work adds to existing knowledge, theory, and thinking in the field. Many submissions currently fail to set the work in the context of the existing literature, and so, we will continue to reject manuscripts that do not clearly build on current knowledge and understanding or appear to provide limited contributions.

We are now requiring all submissions to include a brief, bulleted statement (maximum 100 words) that describes what the paper adds to knowledge in the disciplines of implementation or dissemination science. We 


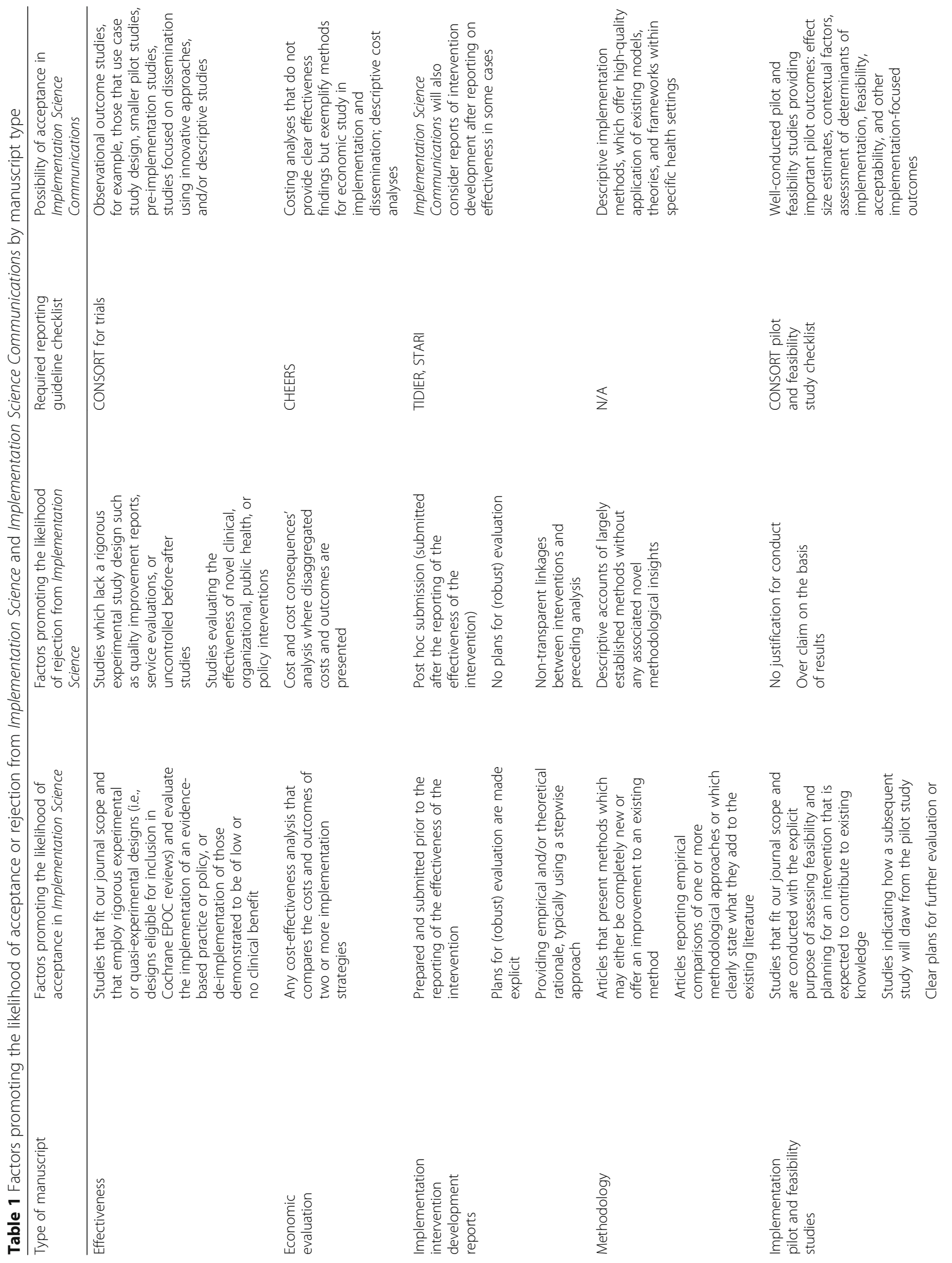



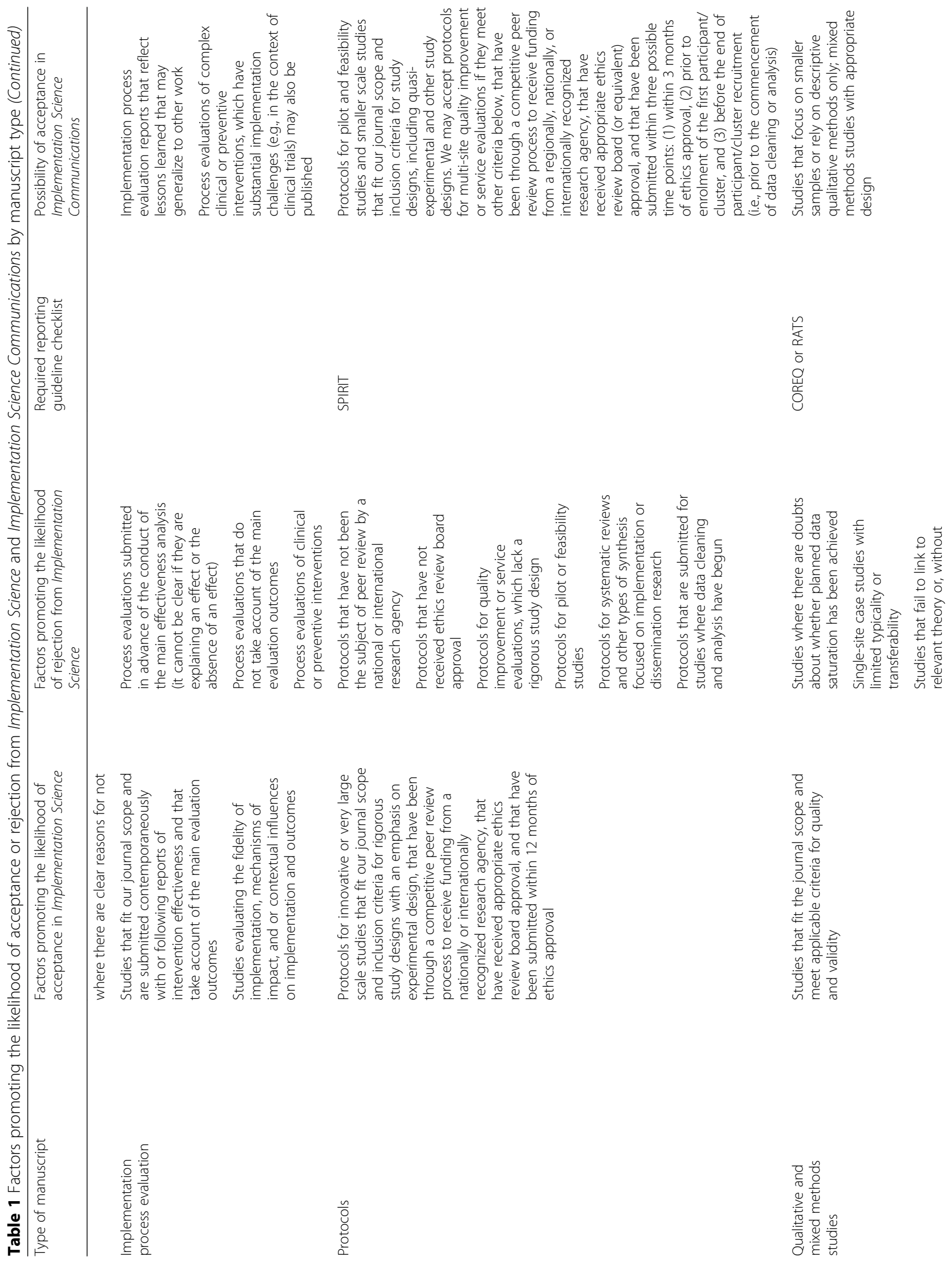


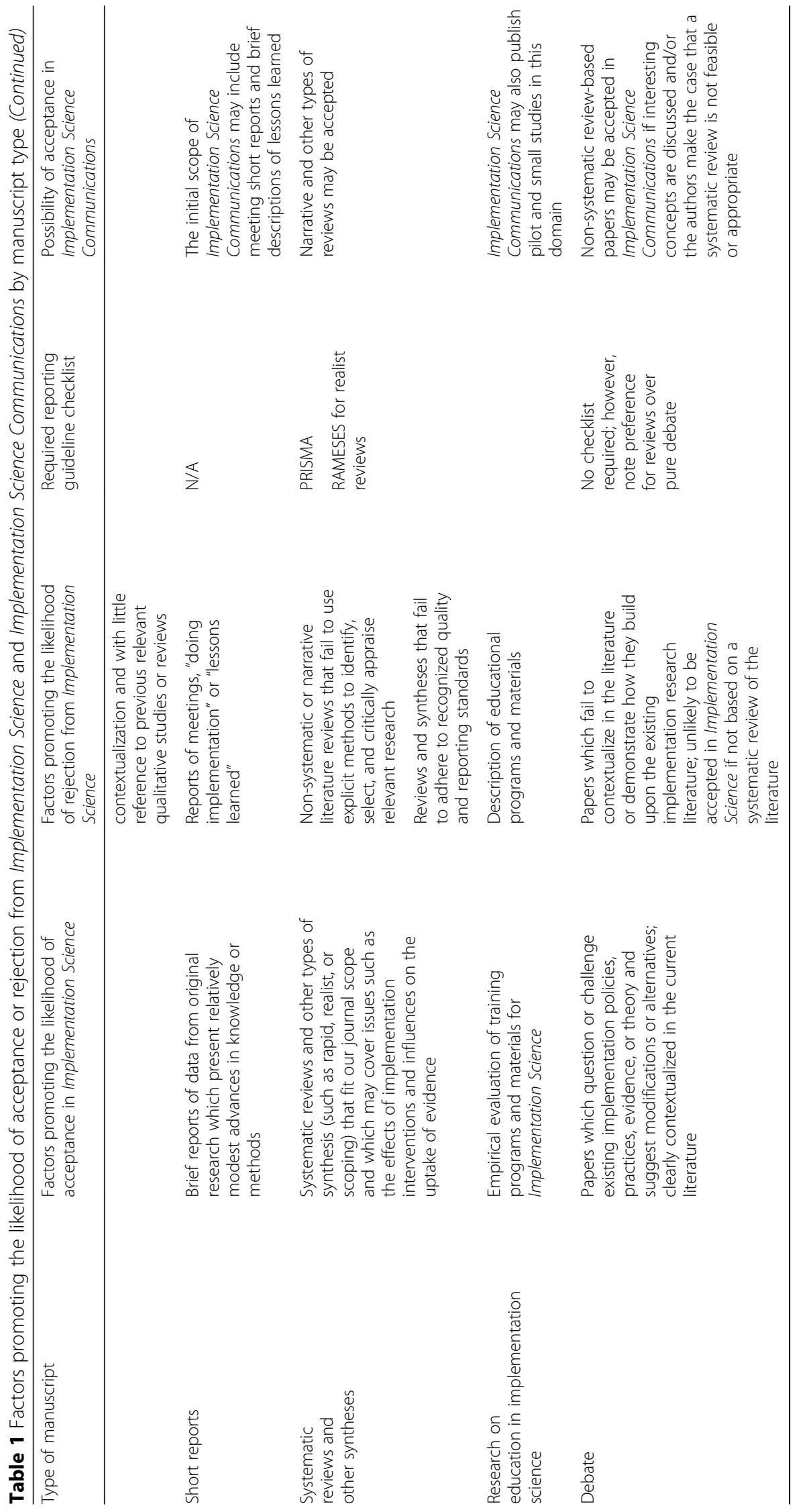


will use this information, which should not be a restatement of the abstract, to evaluate priority for review and in assessing whether a manuscript submitted to Implementation Science should be transferred to Implementation Science Communications. As noted above, both journals require this information.

\section{Open science}

As open access journals (with open peer review), we are committed to making research and the datasets upon which it is based, publicly accessible. A number of different data sharing approaches have now been adopted across the health and medical literature [15]. We have adopted the policies on data availability of our publisher BMC. As part of online article submission, we now ask authors to include an "Availability of data and materials" section in their manuscript detailing the conditions under which the data supporting their findings can be accessed. Authors who do not wish to share their data must include a formal statement that data will not be shared and explain why. Full details of BMC policies can be found under the submission guidelines section of our website. Again, this is true for both journals.

\section{Conclusion}

In this editorial, we have set our expectations for the scientific reporting, quality, and transparency of the manuscripts we currently receive in Implementation Science, and we expect to receive in Implementation Science Communications. We encourage prospective authors to familiarize themselves with the journal scope and boundaries before making a submission and to consider carefully which one of the two journals offers the best fit for a study's scope and methods. We look forward to the next decade as the field continues to grow and evolve and to receiving research that continues to enhance the uptake of evidence-based practices or policies to improve the quality and delivery of healthcare.

\section{Acknowledgements}

We thank our Editorial Board members who have contributed to our on-going discussions about our mission and scope. We are grateful to all the authors who have submitted manuscripts and to our reviewers and Editors who have taken time to assess their suitability for publication in Implementation Science.

\section{Authors' contributions}

AS, PMW, MW, GAA, RA, SF, AH, JP, AR, NS, JS, SS, and BJW have been involved in discussions about journal scope and mission. AS and PMW drafted the initial manuscript and revised it in the light of comments from all other authors. All authors read and approved the final manuscript.

\section{Funding}

Not applicable

\section{Availability of data and materials}

Not applicable

Ethics approval and consent to participate Not applicable
Consent for publication

Not applicable

\section{Competing interests}

The authors all hold editorial positions with Implementation Science. PMW receives funding from the National Institute for Health Research Collaboration for Leadership in Applied Health Research and Care (NIHR CLAHRC) Greater Manchester. AR and NS receive funding from the NIHR CLAHRCs Wessex and South London, respectively. NS is the director of the London Safety and Training Solutions Ltd.

\section{Author details}

'Department of Veterans Affairs Center for Clinical Management Research, VA Ann Arbor Healthcare System, 300 N. Ingalls Street, Suite 1161, Ann Arbor, MI 48109-5430, USA. ${ }^{2}$ Department of Learning Health Sciences, University of Michigan, Ann Arbor, USA. ${ }^{3}$ Alliance Manchester Business School, University of Manchester, Manchester, UK. ${ }^{4}$ University of Heidelberg, Heidelberg, Germany. ${ }^{5}$ University of California, San Diego, USA. ${ }^{6}$ Australian Institute of Family Studies, Melbourne, Australia. ${ }^{7}$ Norwegian Knowledge Centre for the Health Services, Oslo, Norway. ${ }^{8}$ Deakin University, Monash Health, Clayton, Australia. ${ }^{9}$ Ottawa Hospital Research Institute, Ottawa, Canada. ${ }^{10}$ University of Southampton, Southampton, UK. ${ }^{11}$ King's College London, London, UK. ${ }^{12}$ University of Ottawa, Ottawa, Canada. ${ }^{13}$ University of Toronto, Toronto, Canada. ${ }^{14}$ University of Washington, Seattle, USA.

Received: 30 June 2019 Accepted: 1 July 2019

Published online: 06 August 2019

\section{References}

1. Wilson PM, Sales A, Wensing M, Aarons GA, Flottorp S, Glidewell L, Hutchinson A, Presseau J, Rogers A, Sevdalis N, et al. Enhancing the reporting of implementation research. Implement Sci. 2017;12(1):13.

2. Cochrane Effective Practice and Organisation of Care: Effective practice and organisation of care: EPOC resources for review authors. Norwegian Knowledge Centre for Health Services 2014. Available at: http://epoc. cochrane.org/epoc-specific-resources-review-authors.

3. Curran GM, Bauer M, Mittman B, Pyne JM, Stetler C. Effectivenessimplementation hybrid designs: combining elements of clinical effectiveness and implementation research to enhance public health impact. Med Care. 2012;50(3):217-26.

4. Maru S, Nirola I, Thapa A, Thapa P, Kunwar L, Wu WJ, Halliday S, Citrin D, Schwarz R, Basnett I, et al. An integrated community health worker intervention in rural Nepal: a type 2 hybrid effectiveness-implementation study protocol. Implement Sci. 2018;13(1):53.

5. Swindle T, Johnson SL, Whiteside-Mansell L, Curran GM. A mixed methods protocol for developing and testing implementation strategies for evidence-based obesity prevention in childcare: a cluster randomized hybrid type III trial. Implement Sci. 2017;12(1):90.

6. Hoomans T, Severens J. Economic evaluation of implementation strategies in health care. Implement Sci. 2014;9.

7. Tabak R, Khoong E, Chambers D, Brownson R. Bridging research and practice: models for dissemination and implementation research. Am J Prev Med. 2012:43(3):337-50.

8. Nilsen P. Making sense of implementation theories, models and frameworks Implement Sci. 2015;10:53.

9. Birken SA, Powell BJ, Shea CM, Haines ER, Alexis Kirk M, Leeman J, Rohweder C, Damschroder L, Presseau J. Criteria for selecting implementation science theories and frameworks: results from an international survey. Implement Sci. 2017;12(1):124.

10. Lewis CC, Klasnja P, Powell BJ, Lyon AR, Tuzzio L, Jones S, Walsh-Bailey C, Weiner B. From classification to causality: advancing understanding of mechanisms of change in Implementation Science. Front Public Health. 2018;6:136.

11. Eccles MP, Mittman BS. Welcome implementation. Sci Implementation Sci. 2006; 1 .

12. Recommendations for the conduct, reporting, editing, and publication of scholarly work in medical journals [http://icmje.org/news-and-editorials/ icmje-recommendations_annotated_dec16.pdf]

13. Hoffmann TC, Glasziou PP, Boutron I, Milne R, Perera R, Moher D, Altman $D G$, Barbour V, Macdonald H, Johnston M, et al. Better reporting of 
interventions: template for intervention description and replication (TIDieR) checklist and guide. BMJ. 2014;348:g1687.

14. Cotterill S, Knowles S, Martindale AM, Elvey R, Howard S, Coupe N, Wilson P, Spence M. Getting messier with TIDieR: embracing context and complexity in intervention reporting. BMC Med Res Methodol. 2018;18(1):12.

15. Barbui C. Sharing all types of clinical data and harmonizing journal standards. BMC Med. 2016;14(1):63.

\section{Publisher's Note}

Springer Nature remains neutral with regard to jurisdictional claims in published maps and institutional affiliations.

Ready to submit your research? Choose BMC and benefit from:

- fast, convenient online submission

- thorough peer review by experienced researchers in your field

- rapid publication on acceptance

- support for research data, including large and complex data types

- gold Open Access which fosters wider collaboration and increased citations

- maximum visibility for your research: over $100 \mathrm{M}$ website views per year

At BMC, research is always in progress.

Learn more biomedcentral.com/submissions 